\title{
AN EXPERIMENTAL STUDY OF AN EDUCATIONAL INTERVENTION TO CHANGE GOAL ORIENTATION
}

\author{
Mai Yokoyama and Kazuhisa Miwa \\ Nagoya University, Japan
}

\begin{abstract}
This study examined the effects of intervention with a $2 \times 2$ factor manipulation, identifying the effects of evaluation indicators (presentation/construction) and evaluator (self/peer) on students' goal orientation. Specifically, we created five groups (one control group and four experimental groups) and conducted experimental lessons. The learning topic was debate training. The participants were 67 first-year students. Analyses focusing on the cross-lagged relationships of goal orientation before and after the intervention were performed. The effects of the intervention on goal orientation may depend on the individual student's initial goal orientation. By increasing the level of the intervention, students' initial goal orientation might have a greater effect on the goal orientation that the student exhibited after the intervention. The results of this study give guidelines on the learning intervention according to student's initial goal orientation.
\end{abstract}

\section{KEYWORDS}

Goal orientation, Intervention, Cross-Lagged Relationships

\section{INTRODUCTION}

\subsection{Goal Orientation}

Goal-achievement theory (Dweck 1986), which accounts for differences in learning behavior in terms of what each student's goals are as they execute tasks, classifies such goals into two categories: learning and performance goals. The purpose of the former is to acquire new knowledge and skills through challenging activities while that of the latter is to seek positive and avoid negative evaluations. Students with learning goals tend to select challenging tasks and persevere even when they encounter failure, regardless of whether they are confident in their abilities. Performance-oriented appear similar to students with the learning orientation, provided they are confident in their abilities; however, if they lack confidence, they are less likely to persevere until they have completed the given tasks. Elliot and Dweck's (1988) findings support the latter statement. Ames and Archer $(1987,1988)$ note that learning goals have a positive effect on both academic achievement and endogenous motivation; learning goals are generally considered superior for attaining learning achievement.

Elliot and Harackiewicz (1996) divided performance goals into a performance-approach goals, in which a student tries to outperform others, and performance-avoidance goals, or attempting to avoid performing worse than others. Elliot and Church (1997) and Rawsthorne and Elliot (1999), among others, have found that performance-approach goals lead to positive effects on endogenous motivation and academic performance, but performance-avoidance goals have negative effects, thus demonstrating the importance of distinguishing between the approach and avoidance utilities.

\subsection{Stability and Change in Goal Orientation}

These perspectives treat goal orientation either as a personality characteristic- goal orientation is considered to be consistent and not to depend on the learning context — or a controllable characteristic - goal orientation is induced by the learning environment (DeShon \& Gillespie 2005). We take the latter position here and 
create an intervention intended to change the student's goal orientation. Fryer and Elliot (2007) and Muis and Edwards (2009) examined stability and change in students' goal orientations. These studies indicate that goal orientation is relatively stable, but there is the possibility that it may change in response to certain situations. It is important to account for both stability and change in goal orientation (Fryer \& Elliot 2007). Changes in goal orientation in response to interventions may be affected by the initial goal orientation of the student.

\subsection{Feedback as Change Agent for Goal Orientation}

Winne et al. (2003) intervened in students' goal orientation using feedback and examined the resulting changes in goal orientation. They found that positive feedback resulted in decreases in the performance-avoidance goal orientation, and negative feedback resulted in decreases in the performance-approach goal orientation. However, no increase in the learning-goal orientation was found. Geitz et al. (2015) intervened in students' goal orientation with feedback, using the method indicated by Boud and Molloy (2013), and they examined the effects on goal orientation and learning behavior. The intervention did not influence goal orientation directly, but it helped goal-oriented students maintain deep learning.

The findings of Winne et al. (2003) made it clear that feedback could play a role in changing goal orientation, and Geitz et al. (2015) suggested that the effectiveness of feedback intervention depends on the initial goal orientation of the student. We assumed that the effects of changing goal orientation through feedback intervention depends on the initial goal orientation of the student.

\subsection{Self-Evaluation / Peer-Evaluation}

In this study, we manipulated two factors. The first was the evaluator. It is important who provides feedback. According to Boud and Molly (2013), to create effective feedback, it is necessary for students to be actively involved in their own learning and to be agents of their own change. In this study, to increase the involvement of students in their learning, we adopted a self-evaluation, in which students provide themselves with feedback, and a peer-evaluation, in which students give feedback to each other, in the place of any evaluation from teachers.

Peer-evaluation has been found to improve student motivation (Asghar 2010), and it encourages students to draw each other's attention to what they know and do not know (Topping 2005; Ladyshewsky \& Ryan 2006). Thus, peer-evaluation was expected to be more effective in enhancing student involvement in their learning process than self-evaluation was. Peer-evaluation was considered to be the higher level of intervention.

\subsection{Presentation / Construction of Evaluation Indicators}

The second factor concerned evaluation indicators. We examined the effects of presenting evaluation indicators to students in advance using rubrics, in one manipulation, while in another, we let students make rubrics themselves, meaning that they were responsible for identifying indicators. Rubrics are assessment tools that articulate specific expectations for assignments by listing the criteria for higher marks, identifying what is particularly important in students' work, and describing levels of quality on a scale from excellent to poor (Panadero \& Romero 2014). The standard usage is to present students with rubrics constructed by teachers, but Anderson (1998) recommends that students be involved in constructing them. In this way, students can gain awareness of their own involvement in their learning and can be expected to take tasks seriously (Steaven \& Levi 2013). The intervention of having students construct evaluation indicators themselves was expected to be more effective for enhancing involvement in learning than the intervention in which evaluation indicators were presented in advance and represented a higher level of intervention.

\subsection{Purpose}

This study examined the effects of intervention with a $2 \times 2$ factor manipulation, identifying the effects of evaluation indicators (presentation/construction) and evaluator (self/peer) on students' goal orientation. 
Specifically, we created five groups: one control group (Control Group) and four experimental groups (Presentation-Self Group, Construction-Self Group, Presentation-Peer Group, Construction-Peer Group) and conducted experimental lessons. Because the level of intervention for Construction was higher than for Presentation, and the level of intervention for Peer was higher than for Self, the relationships of expected effects were as follows.

Control Group < Presentation-Self Group < Construction-Self Group, Presentation-Peer Group $<$ Construction-Peer Group

Two analyses focusing on the cross-lagged relationships of goal orientation before and after the intervention were performed, as described below. Analysis 1 revealed the cross-lagged relationships of each group regarding goal orientation using multi-group structural equation modeling (SEM) analysis. Analysis 2 identified the path-coefficient differences between the control group and each of the four experimental groups and clarifies the characteristics of each group by comparison with the control group, which is taken to be the baseline.

\section{METHOD}

We intervened in classes held in a public university in 2018. The learning topic was debate training, as the student-centered learning was more likely to increase the involvement of students in learning and to change their goal orientation. Classes were held five times every other week. The participants were 67 first-year students (Control Group: $\mathrm{N}=14$; Presentation-Self Group: $\mathrm{N}=14$; Construction-Self Group: $\mathrm{N}=13$; Presentation-Peer Group: $\mathrm{N}=13$; Construction-Peer Group: $\mathrm{N}=13$ ). Each group was subsequently divided into three smaller groups (three to five students per group). Table 1 shows the class procedure.

Table 1. Class Procedure

\begin{tabular}{cl}
\hline Week 1 & $\cdot$ Pre-test $(10 \mathrm{~min}) \cdot$ Watching an introduction video of debate discussion $(60 \mathrm{~min})$ \\
& $\cdot$ Evaluation indicators (presentation/construction) $(20 \mathrm{~min})$ \\
\hline Week 2 & $\cdot$ Practice for debate $(90 \mathrm{~min})$ \\
\hline Week 3 & $\cdot$ Preparing for match up debate $(90 \mathrm{~min})$ \\
\hline Week 4 & $\cdot$ Preparing for match up debate $(45 \mathrm{~min}) \cdot$ Evaluating performance: evaluator $($ self/peer $)(45 \mathrm{~min})$ \\
\hline Week 5 & $\cdot$ Match up debate $(80 \mathrm{~min}) \cdot$ Post-test $(10 \mathrm{~min})$ \\
\hline
\end{tabular}

\section{Pre-test and post-test}

The questionnaire comprised 18 items, which was modified from Mitsunami (2010) translated in Japanese from the Achievement Goal Scale developed by Elliot and Church (1997).

Evaluation indicators (presentation/construction)

We explained to the students in the four experimental groups that a rubric is a tool for indicating a desired goal and its evaluation indicators. Teacher-constructed rubrics were distributed to students of the two Presentation Groups. Empty sheets were provided for students of the two Construction Groups. These students were asked to carefully consider the goals that they wished to achieve through studying their lessons and to fill in the evaluation items and their level. Each group constructed one rubric.

\section{Evaluator (self/peer)}

We explained to the students in the four experimental groups that the purpose of evaluation is to improve learning behaviors to achieve a goal. The students in the two Self Groups conducted self-evaluation, and students in the two Peer Groups conducted peer-evaluations, adapting the evaluation indicators of the rubric, which was presented or constructed during the first week.

\section{RESULTS}

The responses of 63 subjects who attended lessons during weeks 1,2, and 5 and responded to all questions in the questionnaire were analyzed. The model fit was using by the comparative fit index (CFI) and the root 
mean square error of approximation (RMSEA). Values above .95 for CFI and below .07 for RMSEA were regarded as indicating sufficient fit (Hooper et al. 2008).

\subsection{Confirmatory Factor Analysis}

A confirmatory factor analysis was performed to test the three-factor structure, composed of the learning goal (LG), performance-approach goal (PAPG), and performance-avoidance goal (PAVG). We excluded three items that had a factor loading of .40 or less; as a result, the above criterion was satisfied: CFI-pre $=.963$, RMSEA-pre $=.047$, CFI-post $=.955$, RMSEA-post $=.061$. Table 2 shows the Cronbach's $\alpha$ coefficient and the items for each factor. The average value for the items was regarded as the respective value for each factor.

Table 2. Items and $\alpha$ Coefficient



\subsection{Mixed-design Analysis of Variance}

A mixed-design analysis of variance (mixed-design ANOVA) of group (five groups) $\times$ time (pre, post) was performed. Table 3 shows the results of this ANOVA. A marginally significant main effect of time was found for LG, but no other significant effect was found. The results of the mixed-design ANOVA show no effect of intervention on goal orientation.

Table 3. Results for Mixed-Design ANOVA

\begin{tabular}{|c|c|c|c|c|c|c|c|c|c|c|c|c|c|}
\hline & \multicolumn{2}{|c|}{ Control } & \multicolumn{2}{|c|}{$\begin{array}{c}\text { Presentation } \\
\text {-Self }\end{array}$} & \multicolumn{2}{|c|}{$\begin{array}{c}\text { Construction } \\
\text {-Self }\end{array}$} & \multicolumn{2}{|c|}{$\begin{array}{c}\text { Presentation } \\
\text {-Peer }\end{array}$} & \multicolumn{2}{|c|}{$\begin{array}{l}\text { Construction } \\
\text {-Peer }\end{array}$} & \multirow[t]{2}{*}{$\begin{array}{l}\text { Group } \\
\text { (df) }\end{array}$} & \multirow[t]{2}{*}{$\begin{array}{l}\text { Time } \\
\text { (df) }\end{array}$} & \multirow{2}{*}{$\begin{array}{c}\text { Interac } \\
\text { tion } \\
\text { (df) }\end{array}$} \\
\hline & mean & SD & mean & SD & mean & SD & mean & SD & mean & SD & & & \\
\hline LG-pre & 3.82 & 0.71 & 3.83 & 0.67 & 3.85 & 0.55 & 3.90 & 0.43 & 4.25 & 0.37 & 1.24 & $3.26+$ & 0.68 \\
\hline LG-post & 3.91 & 0.77 & 4.08 & 0.70 & 3.83 & 0.40 & 4.04 & 0.41 & 4.29 & 0.52 & (4) & (1) & (4) \\
\hline PAPG-pre & 3.30 & 0.76 & 3.15 & 0.84 & 3.44 & 0.59 & 3.32 & 0.60 & 3.56 & 0.77 & 0.65 & 2.66 & 0.12 \\
\hline PAPG-post & 3.14 & 0.79 & 3.09 & 0.80 & 3.40 & 0.66 & 3.18 & 0.53 & 3.44 & 0.77 & (4) & (1) & (4) \\
\hline PAVG-pre & 3.90 & 0.64 & 3.55 & 0.84 & 3.83 & 0.44 & 3.83 & 0.52 & 3.93 & 0.64 & 0.80 & 2.02 & 1.03 \\
\hline PAVG-post & 3.54 & 0.84 & 3.51 & 1.03 & 3.87 & 0.45 & 3.67 & 0.41 & 3.95 & 0.55 & (4) & (1) & (4) \\
\hline
\end{tabular}




\subsection{Cross-Lagged Model}

To examine the cross-lagged relationships among LG, PAPG, and PAVG between pre- and post-intervention, we hypothesized a cross-lagged model. SEM served as the basis for exploring the relationships among variables in the cross-lagged model. The results of an SEM analysis to determine whether the cross-lagged model fit was acceptable, the criterion was satisfied: $\mathrm{CFI}=1.00, \mathrm{RMSEA}=.00$.

Analysis 1: Multi-group structural equation modeling analysis

We conducted a multi-group SEM analysis to determine whether the cross-lagged model fit was acceptable among the groups. We excluded the path from PAVG-pre to PAPG-post, which was not significant at the $10 \%$ level for any group; as a result, the criterion was satisfied: $\mathrm{CFI}=.995$, RMSEA $=.034$.

Figure 1 shows the cross-lagged model for each group. Determination coefficients, error variables, correlation paths and their path coefficients, and autoregressive paths (e.g., LG-pre $\rightarrow$ LG-post) and their path coefficients are omitted from Fig. 1 for clarity. The autoregressive path coefficients account for the stability of each answer between pre- and post-intervention. Most autoregressive path coefficients in all groups were significant at $5 \%$ level. The exceptions were the effects of PAVG-pre on PAVG-post (significant at the $10 \%$ level) in Control Group and the effect of PAVG-pre on PAVG-post in the Construction-Self Group (n. s.).

The results of the cross-lagged effects are described below. In the Control Group and Presentation-Self Group, no significant cross-lagged effects were found. In the Construction-Self Group, PAPG-pre had a positive effect $(\beta=.65)$ on LG-post. In the Presentation-Peer Group, LG-pre had a positive effect $(\beta=.30)$ on PAPG-post; PAPG-pre had a positive effect $(\beta=.52)$ on LG-post; and PAVG-pre had a negative effect $(\beta=-.46)$ on LG-post. In the Construction-Peer Group, LG-pre had a negative effect $(\beta=-.45)$ on PAVG-post; PAPG-pre had positive effects on LG-post $(\beta=.75)$ and PAVG-post $(\beta=.35)$; PAVG-pre had a negative effect $(\beta=-.94)$ on LG-post.



a. Control Group

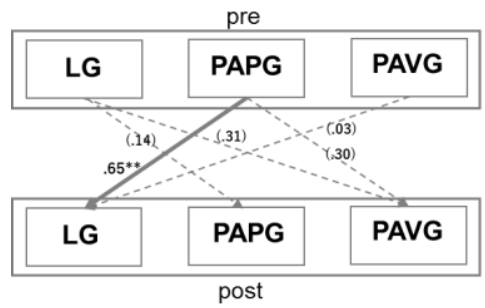

c. Construction-Self Group



e. Construction-Peer Group



b. Presentation-Self Group

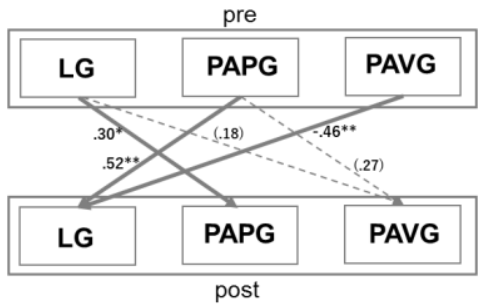

d. Presentation-Peer Group

Note.

Values on the path are normalized coefficients

$\left({ }^{* * *} p<.001,{ }^{* *} p<.01,{ }^{*} p<.05, p<.10\right)$

Paths which are not significant at $10 \%$ level are indicated by

broken lines, normalization factors are indicated in

parentheses.

Figure 1. Cross-lagged Model for Each Group 


\section{Analysis 2: Test for path-coefficient differences}

We tested for measurement invariance to determine whether path coefficients differed significantly between the control group and the four experimental groups. Figure 2 indicates whether the path coefficients in the four experiment groups differ significantly at the $10 \%$ level compared to the Control Group.

No path coefficient exhibiting a significant difference between the Control Group and the Presentation-Self Group. The path coefficient from PAPG-pre to LG-post differed significantly between the Control Group and the Construction-Self Group $(\mathrm{z}=1.82, \mathrm{p}<.10)$. Two path coefficients from PAPG-pre to LG-post $(\mathrm{z}=1.71, \mathrm{p}<.10)$ and from the PAVG-pre to LG-post $(\mathrm{z}=1.72, \mathrm{p}<.10)$ differed significantly between the Control Group and the Presentation-Peer Group. Three paths from LG-pre to PAVG-post $(\mathrm{z}=2.17, \mathrm{p}<.05)$, from PAPG-pre to LG-post $(\mathrm{z}=2.08, \mathrm{p}<.05)$, and from PAVG-pre to LG-post $(\mathrm{z}=2.62, \mathrm{p}<.01)$ differed significantly between the Control Group and the Construction-Peer Group.
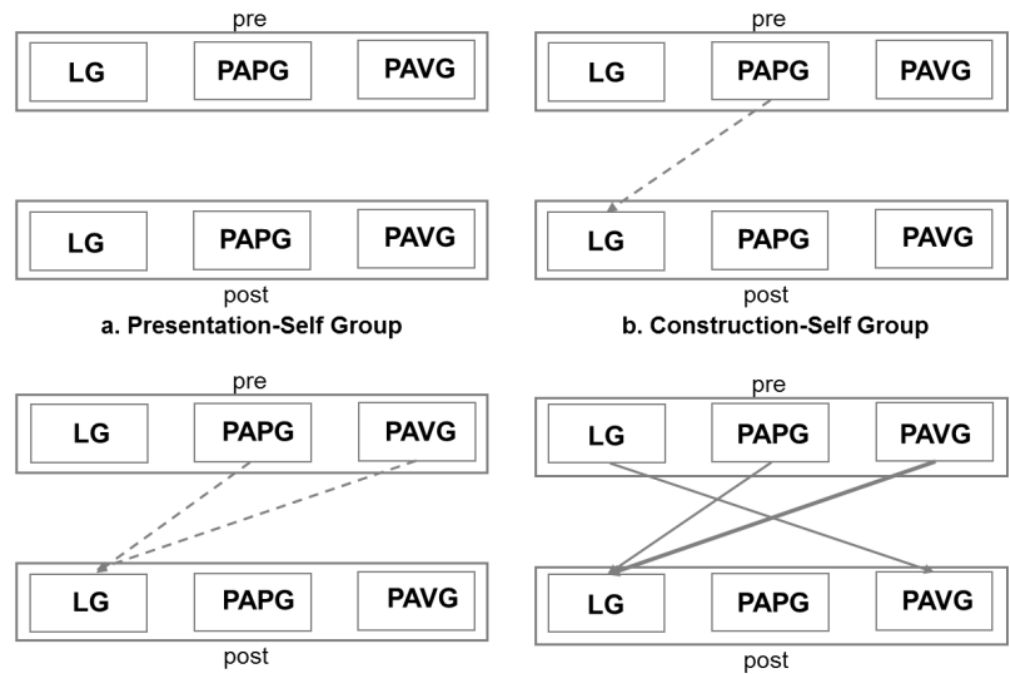

c. Presentation-Peer Group

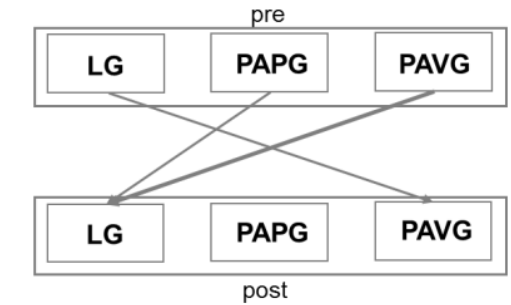

d. Construction-Peer Group

Note. Dashed line shows significant at $10 \%$ level, solid line shows significant at $5 \%$ level, thick solid line shows significant at $1 \%$ level.

Figure 2. Paths Exhibiting Significant Difference

\section{DISCUSSION}

\subsection{Effects of the Intervention}

This was a $2 \times 2$ factor study, measuring evaluation indicators (presentation/construction) and evaluator (self/peer) on goal orientation were manipulated. The results, assessed using mixed-design ANOVA, showed no salient features. The results of analysis 1 and 2, nevertheless, indicated that there were differences in the effects of intervention among the groups, and these effects were shown. These results showed that the effects of the intervention on goal orientation may depend on the individual student's initial goal orientation. In other words, simple analyses of changes in goal-orientation scores before and after the intervention (Winne et al. 2003; Geitz et al. 2015) are insufficient for finding the effects of an intervention. Instead, it should be concluded that the effects of the intervention were affected by the individual student's initial goal orientation. This study provides a new perspective for intervention studies that change goal orientation.

In analysis 1, cross-lagged relationships for goal orientation were examined for each group. No significant cross-lagged effect was found in the Control Group or the Presentation-Self Group, while there was a significant cross-lagged effect for the Construction-Self Group, three significant cross-lagged effects in the Presentation-Peer Group, and four significant effects in the Construction-Peer Group. In analysis 2, we tested for measurement invariance to examine whether path coefficients significantly differed between the control group and each of the four experiment groups. There was no path coefficient found that exhibited a significant difference between the Control Group and the Presentation-Self Group, while there were path 
coefficients that exhibited a significant difference between the Control Group and each of the other experimental groups (Construction-Self Group: one path coefficient; Presentation-Peer Group: two path coefficients; and Construction-Peer Group: three path coefficients). The results of analysis 1 and 2 suggest that by increasing the level of the intervention, students' initial goal orientation might have a greater effect on the goal orientation that the student exhibited after the intervention. Because there was no difference between the Presentation-Self Group and the Control Group, self-evaluation using given evaluation indicators may not be sufficient for obtaining the effects of the intervention.

\subsection{The Cross-Lagged Relationships}

The results of this study give guidelines on the intervention according to student's initial goal orientation. We discuss this below in three ways.

Performance-approach goal-pre $\rightarrow$ learning goal-post

In the Construction-Self, Presentation-Peer, and Construction-Peer Groups, PAPG-pre had a greater positive effect on LG-post than the Control Group. Increasing levels of intervention for students who wanted to be evaluated positively (PAPG-pre) may promote their interest in understanding the contents and/or improving their skills (LG-post). It was suggested that it would be effective for students with a high performance-approach goal orientation to construct evaluation indicators or conduct peer-evaluations.

Performance-avoidance goal-pre $\rightarrow$ learning goal-post

In the Presentation-Peer Group and the Construction-Peer Group, PAVG-pre had a greater negative effect on LG-post than the Control Group. Because this effect was seen in the two Peer groups but not in the two Self groups, peer-evaluation may be the decisive factor here. Students who wanted to avoid being evaluated negatively (PAVG-pre) may have suppressed their interest in understanding content and/or improving their skills (LG-post) due to being evaluated by others. This result indicates that designing situations to receive evaluation from others may not be effective for students with a high performance-avoidance goal orientation.

\section{Learning Goal-pre $\rightarrow$ performance-avoidance goal-post}

Third, in the Construction-Peer Group, LG-pre had a greater negative effect on PAVG-post than in the Control Group. Students who were trying to understand the contents and improve their abilities (LG-pre) and were evaluated by their peers according to their own evaluation indicators were able to increase their understanding of the significance of evaluation and reduce their fear of being evaluated (PAVG-post). This suggests that for students with a high learning goal orientation, combining their own construction of evaluation indicators and peer-evaluations may be effective.

\section{FUTURE WORK}

This study investigated students' goal orientation by manipulating evaluation indicators (presentation/construction) and evaluator (self/peer). The overall results indicated that the intervention had positive effects for students with a high learning goal orientation or a performance-approach goal orientation, but it had negative effects for students with a high performance-avoidance goal orientation. In the future, effective methods for students with a high performance-avoidance goal orientation should be carefully considered.

The multiple goal perspective (Elliot 1999; Harackiewicz et al. 2002; Pintrich 2000) indicates that students could endorse different levels for multiple goals. For example, they could endorse high levels of both the performance-approach goal and the performance-avoidance goal at the same time. This then indicated another future task, namely, to explore the effects of intervention on students with multiple goals.

\section{ACKNOWLEDGMENTS}

The authors are deeply grateful to the teachers who cooperated in the class and the participants of the class. This work was partially supported by JSPS KAKENHI Grant Number $15 \mathrm{H} 02927$. 


\section{REFERENCES}

Ames, C., \& Archer, J. ,1987. Mothers'beliefs about the role of ability and effort in school learning. Journal of Educational Psychology, Vol.79, pp.409-414.

Ames, C., \& Archer, J. ,1988. Achievement goals in the classroom: Students'learning strategies and motivation process. Journal of Educational Psychology, Vol.80, pp.260-267.

Anderson, R. S. ,1998. Why Talk About Different Ways to Grade? The Shift from Traditional Assessment to Alternative Assessment. New Direction for teaching and Leraning, Vol.74, pp.5-16.

Asghar, A. ,2010. Reciprocal peer coaching as a formative assessment strategy for first year students. Assessment and Evaluation in Higher Education, Vol.35, No. 4, pp.403-417.

Boud, D., \& Molloy, E. ,2013. Feedback in Higher and Professional Education: Understanding It and Doing It Well. Routledge; Abingdon, UK.

DeShon, R. P., \& Gillespie, J. Z. ,2005. A motivated action theory accountof goal orientation. Journal of Applied Psychology, Vol. 90, pp.1096-1127.

Dweck, C. S., 1986. Motivational processes affecting learning. American Psychologist, Vol.41, pp.1040-1048.

Elliot, A. J. ,1999. Approach and avoidance motivation and achievement goals. Educational Psychologist, Vol.34, pp.169-189.

Elliot, A. J., \& Church, M. A.,1997. A hierarchical model of approach and avoidance achievement motivation. Journal of Personality and Social Psychology, Vol.72, pp.218-232.

Elliot, A. J., \& Harackiewicz, J. M., 1996. Approach and avoidance achievement goals and intrinsic motivation: A mediational analysis. Journal of Personality and Social Psychology, Vol.70, pp.461-475.

Elliott, E. S., \& Dweck, C. S. ,1988. Goals: An approach to motivation and achievement. Journal of Personality and Social Psychology, Vol.54, No.1, pp.5-12.

Fryer, J. W., \& Elliot, A. J. ,2007. Stability and Change in Achievement Goals. Journal of Educational Psychology, Vol.99, No. 4, pp.700-714.

Geitz, G., Joosten - Ten Brinke, D., \& Kirschner, P. ,2015. Goal Orientation, Deep Learning, and Sustainable Feedback in Higher Business Education. Journal of Teaching in International Business, Vol. 26, No.4, pp.273-292.

Harackiewicz, J. M., Barron, K. E., Pintrich, P. R., Elliot, A. J., \& Thrash, T. M. ,2002. Revision of achievement goal theory: Necessary and illuminating. Journal of Educational Psychology, Vol.94, pp.638-645.

Hooper, D, Coughlan, J \& Mullen, M ,2008. Structural Equation Modelling: Guidelines for Determining Model Fit. ElectronicJournal of Business Research Methods, Vol.6, No.1, pp.53-60.

Ladyshewsky, R., \& Ryan, J. ,2006. Peer Coaching and Reflective Practice in Authentic Business Contexts: A Strategy to Enhance Competency in Post-Graduate Business Students. In A. Herrignton \& J. Herrington (Eds.), Authentic Learning Environments in Higher Education (pp.61-75). Idea Group Publishing, Hershey PA, USA.

Mitsunami, M. ,2010. Influence of Achievement Motive and Goal Orientation on Learning Behavior : Different in Cognitive Strategies. Japanese Journal of Educational Psychology, Vol.58, pp.348-360.

Muis, K. R., \& Edwards, O. ,2009. Examining the Stability of Achievement Goal Orientation. Contemporary Educational Psychology, Vol.34, No.4, pp.265-277.

Panadero, E., \& Romero, M. ,2014. To rubric or not to rubric? The effects of self-assessment on self-regulation, performance and self-efficacy. Assessment in Education: Principles, Policy \& Practice, Vol.21, No.2, pp.133-148.

Pintrich, P. R. ,2000. Multiple goals, multiple pathways: The role of goal orientation in learning and achievement. Journal of Educational Psychology, Vo.92, pp.544-555.

Rawsthorne, L. J., \& Elliot, A, J. ,1999. Achievement goals and intrinsicmotivation: A meta-analytic review. Personality and Social Psychology Review, Vol.3, pp.326-344.

Stevens, D. \& Levi, Antonia J. ,2013. Introduction to Rubrics: An Assessment Tool to Save Grading Time, Convey Effective Feedback, and Promote Student Learning. Stylus Publishing, Sterling,VA, UAS.

Topping, K. J., 2005. Trends in peer learning. Educational Psychology, Vol.25, pp.631-645.

Winne, Philip H., Krista Muis, \& Dianne L. Jamieson-Noel, 2003. The Stability of Goal Orientation as a Function of Feedback and Calibration of Achievement in a Multi-Assignment Undergraduate Course. American Psychological Association, Chicago, USA. 